\title{
A comparison of demographic, epidemiological and clinical characteristics of hospital influenza-related viral pneumonia patients
}

\author{
Bin Fu' ${ }^{1}$ Z Zhengjie Wu ${ }^{2}$, Lingtong Huang ${ }^{3}$, Zhaohui Chai ${ }^{4}$, Peidong Zheng ${ }^{4}$, Qinmiao Sun ${ }^{5}$, Silan Gu², \\ Qiaomai $X u^{2}$, Haiting Feng ${ }^{6}$ and Lingling Tang ${ }^{2,7^{*}}$ (D)
}

\begin{abstract}
Background: Through the comparison of the demographic, epidemiological, and clinical characteristics of hospital human influenza (influenza A (H1N1) pdm09, H3N2, and B)-related and hospitalized avian-origin influenza A (H7N9)related viral pneumonia patients, find the different between them.

Methods: A retrospective study was conducted in hospitalized influenza-related viral pneumonia patients.

Results: Human influenza A-related patients in the 35-49-year-old group were more than those with B pneumonia patients $(p=0.027)$, and relatively less in the $\geq 65$-year-old group than $B$ pneumonia patients $(p=0.079)$. The proportion of comorbid condition to human influenza A pneumonia was 58\%, lower than B pneumonia and H7N9 pneumonia patients (78\% vs. 77.8\%; $p=0.013$ ). The proportion of invasive mechanical ventilation (IMV), lymphocytopenia, elevated lactate dehydrogenase to hospitalized human influenza A-related viral pneumonia patients was higher than B pneumonia patients $(p<0.05)$, but lower than H7N9 pneumonia patients $(p<0.05)$. In the multivariate analysis, pulmonary consolidation (odds ratio (OR): $13.67 ; 95 \%$ confidence interval $(C I) 1.54-121.12 ; p=0.019$ ) and positive bacterial culture (sputum) (OR: 7.71; $95 \% \mathrm{Cl} 2.48-24.03 ; \mathrm{p}<0.001)$ were independently associated with IMV, while shock (OR: 13.16; 95\% Cl 2.06-84.07; $p=0.006)$, white blood cell count $>10,000 / \mathrm{mm}^{3}(\mathrm{OR}: 7.22 ; 95 \% \mathrm{Cl} 1.47-35.58 ; p=0.015)$ and positive bacterial culture(blood or sputum) (OR: $6.27 ; 95 \% \mathrm{Cl} 1.36-28.85 ; \mathrm{p}=0.018$ ) were independently associated with death in the three types hospitalized influenza-related viral pneumonia patients.

Conclusions: Hospital influenza B-related viral pneumonia mainly affects the elderly and people with underlying diseases, while human influenza A pneumonia mainly affects the young adults; however, the mortality was similar. The hospitalized human influenza A-related viral pneumonia patients was severer than B pneumonia patients, but milder than H7N9 pneumonia patients. Pulmonary consolidation and positive bacterial culture (sputum) were independently associated with IMV, while shock, white blood cell count $>10,000 / \mathrm{mm}^{3}$, and positive bacterial culture (blood or sputum) were independently associated with death to three types hospitalized influenza-related viral pneumonia patients.
\end{abstract}

\footnotetext{
*Correspondence: 1196040@zju.edu.cn

7 Shulan(Hangzhou) Hospital Affiliated to Zhejiang Shuren University

Shulan International Medical College, Hangzhou 310006, People's

Republic of China

Full list of author information is available at the end of the article
}

(c) The Author(s) 2021. Open Access This article is licensed under a Creative Commons Attribution 4.0 International License, which permits use, sharing, adaptation, distribution and reproduction in any medium or format, as long as you give appropriate credit to the original author(s) and the source, provide a link to the Creative Commons licence, and indicate if changes were made. The images or other third party material in this article are included in the article's Creative Commons licence, unless indicated otherwise in a credit line to the material. If material is not included in the article's Creative Commons licence and your intended use is not permitted by statutory regulation or exceeds the permitted use, you will need to obtain permission directly from the copyright holder. To view a copy of this licence, visit http://creativecommons.org/licenses/by/4.0/. The Creative Commons Public Domain Dedication waiver (http://creativeco mmons.org/publicdomain/zero/1.0/) applies to the data made available in this article, unless otherwise stated in a credit line to the data. 
Keywords: Human influenza A, Influenza B, Avian-origin influenza H7N9, Viral pneumonia, Severe cases

\section{Background}

Influenza causes considerable morbidity during each annual influenza season. In April 2009, the influenza A (H1N1) pdm09 (pH1N1) virus emerged in Mexico and the USA and spread globally [1]. Since the first report of pneumonia that was caused by the pH1N1 virus in Mexico [2], severe cases have been documented worldwide. Influenza B virus has been classically considered less pathogenic than influenza A virus in adults and mostly responsible for mild respiratory infections, while severe illness and poor prognosis have been associated with bacterial coinfection [3, 4]. On March 30, 2013, three individuals with severe pneumonia were found to be infected with a novel avian-origin influenza A (H7N9) virus that had not been detected in humans and animals previously. As of May 9, 2013, 131 laboratory-confirmed cases were reported, including 32 deaths [5], and the majority of these patients were reported in China.

The comparison of the demographic, epidemiological, and clinical characteristics of hospital human influenza (influenza A (H1N1) pdm09, H3N2, and B)-related and hospitalized avian-origin influenza A (H7N9)-related viral pneumonia patients has not been reported. 20172018 influenza season was dominated by $\mathrm{pH} 1 \mathrm{~N} 1$ and $\mathrm{B}$ viruses along with co-circulation of $\mathrm{H} 3 \mathrm{~N} 2$ virus, this season provided a unique opportunity to directly compare the demographic, epidemiological, and clinical characteristics of hospitalized human influenza $\mathrm{A}$ ( $\mathrm{pH} 1 \mathrm{~N} 1$ and H3N2)-related viral pneumonia patients to the hospital influenza B-related viral pneumonia patients. Also, we compared the demographic, epidemiological, and clinical characteristics of these hospitalized human influenza (pH1N1, H3N2, and B)-related viral pneumonia patients to the hospital H7N9-related viral pneumonia patients in 2017, and aimed to discover the factors independently associated with invasive mechanical ventilation (IMV) or death among these three types hospitalized influenzarelated viral pneumonia patients.

\section{Methods}

\section{Study design and study population}

A retrospective study was conducted from November 1, 2017 to March 31, 2018 at the First Affiliated Hospital, College of Medicine, Zhejiang University, China. All patients, $>14$ years of age and with hospital stay $>24 \mathrm{~h}$ with confirmed human influenza A or B-related viral pneumonia were included in this study. In addition to above factors, those with confirmed H7N9-related viral pneumonia from January 1, 2017 to May 3, 2017 were also included. This study was approved by the Ethical Board of the hospital.

This retrospective study evaluated the reverse transcriptase-polymerase chain reaction (RT-PCR) tests and computed tomography results daily in hospitalized patients with confirmed human influenza A- or B-related viral pneumonia or H7N9-related viral pneumonia. These cases were assessed by an Infectious Disease doctor and nasopharyngeal swabs (NPS) or sputum specimens were collected within the first $24 \mathrm{~h}$ of hospitalization and processed immediately. Influenza-related viral pneumonia was defined as confirmed human influenza A or B or H7N9 virus infection and the presence of a new infiltrate on computed tomography plus fever or respiratory symptoms. All radiological evaluations were performed by two radiologists who were blinded to the clinical information.

\section{Data collection and definitions}

Clinical data were acquired from electronic medical records. The following variables were recorded: demographics, comorbid conditions, current smoking status, alcohol abuse, pregnancy, body mass index (BMI), clinical feature, laboratory data, radiographic finding, complication, treatment, and clinical outcome. The definitions of obesity, current smoking status, alcohol abuse, confirmed human influenza A or B, confirmed H7N9, lymphocytopenia, thrombocytopenia, rhabdomyolysis, acute kidney injury, immunosuppression, early antiviral therapy, exposure to live poultry and severe cases were provided in Additional file 1.

\section{Statistical analysis}

Categorical variables were compared by the Chi-square or Fisher's exact test. Continuous variables were compared by the t-test or the Mann-Whitney test. The multivariate logistic regression analysis of factors potentially associated with IMV or in-hospital mortality included the variables that were significant in the univariate analysis and clinically important variables. Statistical significance was established at $\mathrm{p}$-value $<0.05$. All statistical analyses were performed using SPSS v.18. (SPSS Inc., Chicago, IL, USA). 


\section{Results}

\section{Demographic and epidemiological characteristics}

From November 1, 2017 to March 31, 2018, a total of 4297 cases of laboratory-confirmed human influenza A and B viral infection were reported in our hospital. Of these, 2335 cases were human influenza A (about $85 \%$ were $\mathrm{pH} 1 \mathrm{~N} 1$ and $15 \%$ were $\mathrm{H} 3 \mathrm{~N} 2$ ), 1880 cases were influenza $\mathrm{B}$, and 82 cases were infected with both viruses. Finally, 138 cases of hospitalized human influenza A-related viral pneumonia and 59 cases of hospitalized influenza B-related viral pneumonia were included in this study. From January 1, 2017 to May 3, 2017, a total of 18 cases of hospitalized H7N9-related viral pneumonia were also included in the current study. The median age of hospitalized human influenza A-related viral pneumonia patients was lower than those with B pneumonia (57 years (interquartile range (IQR), 45.8-66.3) vs. 62 years (IQR, $53-74) ; \mathrm{p}=0.034$ ). In the 35-49-yearold age group, the proportion of hospitalized human influenza A-related viral pneumonia patients was $23.9 \%$, which was higher than B pneumonia patients (10.2\%; $\mathrm{p}=0.027)$. In the $\geq 65$-year-old group, the proportion of hospitalized human influenza A-related viral pneumonia patients was $32.6 \%$, which was relatively lower than B pneumonia patients $(45.8 \% ; \mathrm{p}=0.079$; Table 1$)$. The proportion of comorbid conditions in hospitalized human influenza A-related viral pneumonia patients was $58 \%$, which was lower than the B pneumonia patients and hospitalized H7N9 pneumonia patients $(78 \%$ vs. $77.8 \% ; \mathrm{p}=0.013)$. Interestingly, $66.7 \%$ of hospitalized

Table 1 Comparison of demographic and epidemiological characteristics of three types hospitalized influenza-related viral pneumonia patients

\begin{tabular}{|c|c|c|c|c|c|}
\hline \multirow[t]{2}{*}{ Characteristics } & \multirow{2}{*}{$\begin{array}{l}B(n=59) \\
\text { (a) }\end{array}$} & \multirow{2}{*}{$\begin{array}{l}A(n=138) \\
\text { (b) }\end{array}$} & \multirow{2}{*}{$\begin{array}{l}\text { H7N9 }(n=18) \\
\text { (c) }\end{array}$} & \multicolumn{2}{|c|}{ p-value among } \\
\hline & & & & (a) and (b) & (a), (b), and (c) \\
\hline \multicolumn{6}{|l|}{ Demographic data } \\
\hline \multicolumn{6}{|l|}{ Age (y) } \\
\hline Median (IQR) & $62(53-74)$ & $57(45.8-66.3)$ & $60(43.3-68)$ & 0.034 & 0.095 \\
\hline \multicolumn{6}{|l|}{ Age subgroup (y), no. (\%) } \\
\hline $14-34$ & $7(11.9)$ & $12(8.7)$ & $1(5.6)$ & 0.49 & 0.752 \\
\hline $35-49$ & $6(10.2)$ & $33(23.9)$ & $4(22.2)$ & 0.027 & 0.08 \\
\hline $50-64$ & 19 (32.2) & $48(34.8)$ & $7(38.9)$ & 0.726 & 0.863 \\
\hline$\geq 65$ & $27(45.8)$ & $45(32.6)$ & $6(33.3)$ & 0.079 & 0.205 \\
\hline Female, no. (\%) & $22(37.3)$ & $49(35.5)$ & $4(22.2)$ & 0.812 & 0.486 \\
\hline \multicolumn{6}{|l|}{ Comorbid conditions, no. (\%) } \\
\hline Any one condition & $46(78.0)$ & $80(58.0)$ & $14(77.8)$ & 0.007 & 0.013 \\
\hline Chronic pulmonary disease & $7(11.9)$ & $20(14.5)$ & $2(11.1)$ & 0.623 & 0.949 \\
\hline Diabetes & $5(8.5)$ & $24(17.4)$ & $2(11.1)$ & 0.106 & 0.289 \\
\hline Hypertension & $21(35.6)$ & $54(39.1)$ & $8(44.4)$ & 0.64 & 0.778 \\
\hline Chronic renal diseases & $5(8.5)$ & $7(5.1)$ & $2(11.1)$ & 0.556 & 0.327 \\
\hline Chronic liver diseases & $7(11.9)$ & $15(10.9)$ & $5(27.8)$ & 0.839 & 0.132 \\
\hline Chronic cardiovascular disease & $5(8.5)$ & $25(18.1)$ & $2(11.1)$ & 0.085 & 0.224 \\
\hline Chronic neurological disease & $4(6.8)$ & $5(3.6)$ & $1(5.6)$ & 0.549 & 0.495 \\
\hline Hematological diseases & $10(16.9)$ & $12(8.7)$ & $0(0)$ & 0.092 & 0.085 \\
\hline Immunosuppression & $7(11.9)$ & $11(8)$ & $0(0)$ & 0.385 & 0.305 \\
\hline Pregnancy & $0(0)$ & $1(0.7)$ & $0(0)$ & 1 & 1 \\
\hline Current smoker & $9(15.3)$ & $36(26.1)$ & $7(38.9)$ & 0.097 & 0.076 \\
\hline Alcohol abuse & $8(13.6)$ & $27(19.6)$ & $3(16.7)$ & 0.312 & 0.633 \\
\hline \multicolumn{6}{|l|}{ BMI, no. (\%) } \\
\hline Obesity + morbid obesity & $0(0)$ & $7(5.1)$ & $0(0)$ & 0.105 & 0.229 \\
\hline $\begin{array}{l}\text { Exposure to live poultry in previous } \\
14 \text { days, no. (\%) }\end{array}$ & NA & NA & $12(66.7)$ & & \\
\hline
\end{tabular}

Body mass index: For human influenza A, there were 40 miss dates; for $B$, there were 18 miss dates; for H7N9, there were 3 miss dates IQR interquartile range 
H7N9-related viral pneumonia patients were exposed to live poultry.

\section{Clinical characteristics and diagnostic findings}

The most common symptoms of the three types of hospital influenza-related viral pneumonia patients were fever, cough, sputum production, shortness of breath, and fatigue (Table 2).

At the time of admission, the proportion of lymphocytopenia in hospitalized human influenza A-related viral pneumonia patients was $83.3 \%$, higher than B pneumonia patients $(69.5 \% ; \mathrm{p}=0.028)$. The proportion of elevated aspartate aminotransferase (AST), lactate dehydrogenase (LDH) in hospitalized human influenza A-related viral pneumonia patients was higher than that of $\mathrm{B}$ pneumonia patients $(46.7 \%$ vs. $25.9 \%, \mathrm{p}=0.007 ; 67.9 \%$ vs. $51 \%$, $\mathrm{p}=0.033$ ). The median value of lymphocyte count in hospitalized H7N9-related viral pneumonia patients was 425/ $\mathrm{mm}^{3}$ (IQR: $375-625$ ), lower than human influenza $\mathrm{A}$ and B pneumonia patients $\left(745 / \mathrm{mm}^{3}\right.$ (IQR: $\left.448-1208\right)$ vs. $1020 / \mathrm{mm}^{3}$ (IQR: $550-1690$ ); $\mathrm{p}=0.001$ ). The proportion of lymphocytopenia in hospitalized H7N9-related viral pneumonia patients was $100.0 \%$, higher than human influenza A and B pneumonia patients (83.3\% vs. $69.5 \%$; $\mathrm{p}=0.006)$. The proportion of elevated AST, creatine kinase (CK), DD, and LDH in hospitalized H7N9-related viral pneumonia patients was higher than human influenza A and B pneumonia patients $(77.8 \%$ vs. $46.7 \%$ vs. $25.9 \%, \mathrm{p}<0.001 ; 76.5 \%$ vs. $17.9 \%$ vs. $9.8 \%, \mathrm{p}<0.001 ; 94.4 \%$ vs. $76.5 \%$ vs. $62.5 \%, \mathrm{p}=0.016 ; 100 \%$ vs. $67.9 \%$ vs. $51 \%$, $\mathrm{p}=0.001$ ). The proportion of positive culture (blood or sputum) on presentation or during hospitalization in the hospitalized H7N9-related viral pneumonia patients (bacterial) was 61.1\%, higher than the human influenza $\mathrm{A}$ and $\mathrm{B}$ pneumonia patients $(21.1 \%$ vs. $21.3 \%$; $=0.002)$.

\section{Complications, treatment, and clinical outcomes}

In the current study, the proportion of intensive care unit (ICU) admission in hospitalized human influenza A-related viral pneumonia patients was $19.6 \%$, which higher than $6.8 \%$ of $B$ pneumonia patients $(p=0.024)$. The proportion of IMV in hospitalized human influenza A-related viral pneumonia patients was $16.7 \%$, which also higher than that in B pneumonia patients $3.4 \%$ $(\mathrm{p}=0.01)$ (Table 3). The proportion of IMV in hospitalized H7N9-related viral pneumonia patients was $38.9 \%$, which was higher than that in human influenza $\mathrm{A}$ and $\mathrm{B}$ pneumonia patients $(16.7 \%$ vs. $3.4 \% ; \mathrm{p}=0.001)$. The median value of hospital expense of hospitalized H7N9related viral pneumonia patients was 66,095.6 Yuan (IQR, 42,450.6-129,574.2), which was higher than that of human influenza A and B pneumonia patients (IQR, $25,642.3$ Yuan $(13,184.5-53,805.7)$ vs. 18,316.8 Yuan
(IQR, 11,111.1-35,750.5); $\mathrm{p}<0.001)$. There was no difference in death to three types of hospitalized influenzarelated viral pneumonia patients.

In the treatment, the rate of glucocorticoid use in hospitalized H7N9-related viral pneumonia patients was $100 \%$, which was higher than human influenza A and B pneumonia patients $(55.8 \%$ vs. $40.7 \%$; $\mathrm{p}<0.001)$. All the hospitalized human influenza A-related viral pneumonia patients and hospitalized influenza B-related viral pneumonia patients were treated with oseltamivir or peramivir or both, and all the hospitalized H7N9-related viral pneumonia patients were treated with a combination of oseltamivir with peramivir. However, the time from onset of illness to administration of antiviral therapy in hospitalized H7N9-related viral pneumonia patients was 4 days (IQR, 3-8.3), which was relatively shorter than that of human influenza $\mathrm{A}$ and $\mathrm{B}$ pneumonia patients (7 days (IQR, $5-10.8$ ) vs. 6 days (range, $3-14$ ); $\mathrm{p}=0.089$ ). The time of administration of antiviral therapy to virusnegative time of hospitalized H7N9-related viral pneumonia patients was 5.5 days (IQR, 2.8-10), shorter than human influenza $A$ and $B$ pneumonia patients (10 days (IQR, 6-14.5) vs. 11 days (IQR, 6-17.75); $\mathrm{p}=0.007$ ).

\section{Factors associated with IMV due to three types hospitalized influenza-related viral pneumonia patients}

In the univariate analysis, the three types hospitalized influenza-related viral pneumonia patients with IMV had significantly higher neutrophil percentage, C-reactive protein, AST, DD, blood urea nitrogen, pro-B-type natriuretic peptides, and partial pressure arterial oxygen/ fraction of inspired oxygen $\left(\mathrm{PaO}_{2}: \mathrm{FiO}_{2}\right)$ levels than the three types hospitalized influenza-related viral pneumonia patients without IMV. Furthermore, the proportion of patients with shortness of breaths, lymphocytopenia, elevated procalcitonin, AST, CK, DD, and LDH, positive bacterial culture (sputum) on presentation or during hospitalization, positive bacterial culture (blood or sputum) on presentation or during hospitalization, CURB-65 score $\geq 2$, bilateral pneumonia, and pulmonary consolidation in the three types of hospitalized influenza-related viral pneumonia patients with IMV was significantly higher than those without IMV, while the lymphocyte count in the three types of pneumonia patients with IMV was lower than those without IMV (Additional file 2: Table S1). In the multivariate analysis, pulmonary consolidation (odds ratio (OR): 13.67; 95\% confidence interval (CI) $1.54-121.12 ; \mathrm{p}=0.019)$ and positive bacterial culture (sputum) at the time of presentation or during hospitalization (OR: 7.71; 95\% CI 2.48-24.03; $\mathrm{p}<0.001$ ) were independently associated with IMV in the three types hospitalized influenza-related viral pneumonia patients (Additional file 4: Table S3). 
Table 2 Comparison of clinical characteristics of three types hospitalized influenza-related viral pneumonia patients

\begin{tabular}{|c|c|c|c|c|c|}
\hline \multirow[t]{2}{*}{ Characteristics } & \multirow{2}{*}{$\begin{array}{l}B(n=59) \\
\text { (a) }\end{array}$} & \multirow{2}{*}{$\begin{array}{l}\text { A }(n=138 \\
\text { (b) }\end{array}$} & \multirow{2}{*}{$\begin{array}{l}\text { H7N9 }(n=18) \\
\text { (c) }\end{array}$} & \multicolumn{2}{|c|}{ p-value among } \\
\hline & & & & (a) and (b) & (a), (b), and (c) \\
\hline \multicolumn{6}{|l|}{ Clinical features } \\
\hline \multicolumn{6}{|l|}{ Fever } \\
\hline Any no. (\%) & $54(91.5$ & $23(89.1)$ & $17(94.4)$ & 0.62 & 0.819 \\
\hline \multicolumn{6}{|c|}{ Maximal temperature subgroup, no $(\%)\left({ }^{\circ} \mathrm{C}\right)$} \\
\hline $37.3-38.0$ & $11(20.4)$ & $12(10.6)$ & $3(18.8)$ & 0.046 & 0.173 \\
\hline $38.1-39.0$ & $25(46.3)$ & $46(40.7)$ & $6(37.5)$ & 0.226 & 0.734 \\
\hline$>39.0$ & $18(33.3)$ & $55(48.7)$ & $7(43.8)$ & 0.213 & 0.174 \\
\hline Cough & $52(88.1)$ & $120(87)$ & $17(94.4)$ & 0.82 & 0.845 \\
\hline Sputum production & $50(84.7)$ & $106(76.8)$ & $16(88.9)$ & 0.209 & 0.348 \\
\hline Shortness of breath & $29(49.2)$ & $83(60.1)$ & $12(66.7)$ & 0.154 & 0.26 \\
\hline Fatigue/weakness & $34(57.6)$ & $67(48.6)$ & $6(33.3)$ & 0.243 & 0.175 \\
\hline Myalgia & $4(6.8)$ & $16(11.6)$ & $1(5.6)$ & 0.305 & 0.617 \\
\hline \multicolumn{6}{|l|}{ Laboratory findings } \\
\hline $\begin{array}{l}\text { White blood cells count } / \mathrm{mm}^{3} \text {, } \\
\text { median (IQR) }\end{array}$ & $6900(4300-12,600)$ & $7000(4300-9550)$ & $4400(3475-5625)$ & 0.407 & 0.008 \\
\hline \multicolumn{6}{|l|}{ Subgroup, no. (\%) } \\
\hline$>10,000 / \mathrm{mm}^{3}$ & $17(28.8)$ & $32(23.2)$ & $1(5.6)$ & 0.403 & 0.12 \\
\hline$<4000 / \mathrm{mm}^{3}$ & $13(22)$ & $28(20.3)$ & $7(38.9)$ & 0.782 & 0.224 \\
\hline $\begin{array}{l}\text { Lymphocytes count } / \mathrm{mm}^{3} \text {, median } \\
\text { (IQR) }\end{array}$ & $1020(550-1690)$ & $745(448-1208)$ & $425(375-625)$ & 0.34 & 0.001 \\
\hline Lymphocytopenia, no. (\%) & $41(69.5)$ & $115(83.3)$ & $18(100)$ & 0.028 & 0.006 \\
\hline Hemoglobulin—g/dL, median (IQR) & $117(95-130)$ & $124(104-139)$ & $117(109.3-129)$ & 0.018 & 0.058 \\
\hline Platelets count/mm³ ${ }^{3}$ median (IQR) & $159,000(107,000-251,000)$ & $164,500(103,300-250,000)$ & $139,000(93,800-173,500)$ & 0.842 & 0.335 \\
\hline Thrombocytopenia, no. (\%) & $26(44.1)$ & $60(43.5)$ & $11(61.1)$ & 0.939 & 0.361 \\
\hline $\begin{array}{l}\text { C-reactive protein > } 10 \text { mg/L, no. } \\
(\%)\end{array}$ & $46(82.1)$ & $115(83.9)$ & $16(88.9)$ & 0.76 & 0.836 \\
\hline Procalcitonin > 0.5 ng/mL, no. (\%) & $8(25.8)$ & $34(31.8)$ & $8(44.4)$ & 0.525 & 0.401 \\
\hline $\begin{array}{l}\text { Alanine aminotransferase }>40 \mathrm{U} / \mathrm{L} \text {, } \\
\text { no. (\%) }\end{array}$ & $15(25.9)$ & $50(36.5)$ & $8(44.4)$ & 0.15 & 0.229 \\
\hline $\begin{array}{l}\text { Aspartate aminotransferase }>40 \\
\text { U/L, no. }(\%)\end{array}$ & $15(25.9)$ & $64(46.7)$ & $14(77.8)$ & 0.007 & $<0.001$ \\
\hline Total bilirubin > $21 \mu \mathrm{mol} / \mathrm{L}$, no. (\%) & $5(8.6)$ & $10(7.3)$ & $0(0)$ & 0.982 & 0.585 \\
\hline $\begin{array}{l}\text { Creatinine }>104 \mu \mathrm{mol} / \mathrm{L} \text { (1.5 mg/ } \\
\mathrm{dL} \text { ), no. (\%) }\end{array}$ & $12(20.3)$ & $19(13.9)$ & $2(18)$ & 0.255 & 0.479 \\
\hline $\begin{array}{l}\text { Lactate dehydrogenase }>250 \mathrm{U} / \mathrm{L} \text {, } \\
\text { no. (\%) }\end{array}$ & $26(51)$ & $91(67.9)$ & $17(100)$ & 0.033 & 0.001 \\
\hline Creatine kinase > 200 U/L, no. (\%) & $5(9.8)$ & $24(17.9)$ & $13(76.5)$ & 0.175 & $<0.001$ \\
\hline $\mathrm{PaO}_{2}: \mathrm{FiO}_{2}(\mathrm{mmHg})$, median (IQR) & $227.5(173.5-302.8)$ & $214.1(136.6-293.2)$ & $171.6(137.5-233.3)$ & 0.214 & 0.118 \\
\hline $\mathrm{PaO}_{2}: \mathrm{FiO}_{2} \leq 300$ mmHg, no. (\%) & $23(71.9)$ & $75(78.1)$ & $16(88.9)$ & 0.47 & 0.41 \\
\hline D-dimer > 700 g/L, no. (\%) & $35(62.5)$ & $104(76.5)$ & $17(94.4)$ & 0.049 & 0.016 \\
\hline \multicolumn{6}{|c|}{ Positive culture (blood or sputum) on presentation or during hospitalization, no. (\%) } \\
\hline Bacterial & $10(21.3)$ & $24(21.1)$ & $11(61.1)$ & 0.975 & 0.002 \\
\hline Fungal & $3(6.4)$ & $18(15.8)$ & $6(33.3)$ & 0.107 & 0.028 \\
\hline \multicolumn{6}{|l|}{ Radiographic findings } \\
\hline \multicolumn{6}{|c|}{ Computed tomography consistent with pneumonia at admission, no. (\%) } \\
\hline Involvement of both lungs & $52(88.1)$ & $121(87.7)$ & $16(88.9)$ & 0.929 & 1 \\
\hline Ground-glass opacity & $12(20.3)$ & $49(35.5)$ & $10(55.6)$ & 0.035 & 0.012 \\
\hline Consolidation & $29(49.2)$ & $88(63.8)$ & $18(100)$ & 0.056 & $<0.001$ \\
\hline CURB-65 score $\geq 2$ & $18(30.5)$ & $38(27.5)$ & $6(33.3)$ & 0.672 & 0.798 \\
\hline
\end{tabular}


Table 2 (continued)

\begin{abstract}
Maximal temperature: For human influenza A, there were 25 miss dates; for $B$, there were 5 miss dates; for H7N9, there were 2 miss dates
$C$-reactive protein: For human influenza $A$, there were 2 miss dates; for $B$, there were 2 miss dates

Procalcitonin: For human influenza $A$, there were 32 miss dates; for $B$, there were 28 miss dates

Alanine aminotransferase: For human influenza $A$, there were 2 miss dates; for $B$, there was 1 miss date

Aspartate aminotransferase: For human influenza $A$, there were 2 miss dates; for $B$, there was 1 miss date

Total bilirubin: For human influenza $A$, there were 2 miss dates; for $B$, there was 1 miss date

Creatinine: For human influenza $A$, there were 2 miss dates

Lactate dehydrogenase: For human influenza $A$, there were 5 miss dates; for $B$, there were 8 miss dates; for H7N9, there were 2 miss dates

Creatine kinase: For human influenza A, there were 5 miss dates; for $B$, there were 8 miss dates; for H7N9, there were 2 miss dates

Partial pressure arterial oxygen/fraction of inspired oxygen: For human influenza $A$, there were 43 miss dates; for $B$, there were 27 miss dates

D-Dimer: For human influenza $A$, there were 3 miss dates; for $B$, there were 3 miss dates

Positive culture (blood or sputum) on presentation or during hospitalization (bacterial): For human influenza A, there were 25 miss dates; for $B$, there were 12 miss dates

Positive culture (blood or sputum) on presentation or during hospitalization (fungal): For human influenza A, there were 25 miss dates; for B, there were 12 miss dates $\mathrm{PaO}_{2}: \mathrm{FiO}_{2}$ partial pressure arterial oxygen/fraction of inspired oxygen, IQR interquartile range
\end{abstract}

\section{Factors associated with death due to the three types} hospitalized influenza-related viral pneumonia patients

In the univariate analysis, the three types of hospitalized influenza-related viral pneumonia patients who die in the hospital had significantly higher neutrophil percentage, hemoglobin, blood platelet counts, C-reactive protein, $\mathrm{DD}$, blood urea nitrogen, pro-B-type natriuretic peptides, and $\mathrm{PaO}_{2}: \mathrm{FiO}_{2}$ levels than the survivors. Also, the proportion of elevated white blood cell count and procalcitonin, positive bacterial culture (sputum) on presentation or during hospitalization, CURB-65 score $\geq 2$, IMV, shock to the three types hospitalized influenzarelated viral pneumonia patients who die in the hospital was significantly higher than that of the survivors (Additional file 3: Table S2). In the multivariate analysis, shock (OR: 13.16; 95\% CI 2.06-84.07; $\mathrm{p}=0.006$ ), white blood cell count $>10,000 / \mathrm{mm}^{3}$ (OR: $7.22 ; 95 \%$ CI 1.47-35.58; $\mathrm{p}=0.015$ ) and positive bacterial culture (blood or sputum) on presentation or during hospitalization (OR: 6.27; 95\% CI 1.36-28.85; $\mathrm{p}=0.018$ ) were independently associated with death in the three types hospitalized influenzarelated viral pneumonia patients (Table 4).

\section{Discussion}

This was the first study that compared the demographic, epidemiological, and clinical characteristics of hospitalized human influenza-related viral pneumonia patients with H7N9 pneumonia patients. The study revealed that the hospitalized human influenza A-related viral pneumonia patients were younger than those with $B$ pneumonia, and the infection was primarily detected in young adults. On the other hand, the influenza B-related viral pneumonia was common in the elderly, usually with comorbid conditions. Hospitalized human influenza A-related viral pneumonia patients was severer than B pneumonia patients, but milder than H7N9 pneumonia patients.

The proportion of patients who have at least one comorbid condition in those with human influenza A-related viral pneumonia was lower than those with B pneumonia and H7N9 pneumonia patients. Moreover, the average age of hospitalized human influenza A-related viral pneumonia patients was lower than that of $B$ pneumonia patients, and the proportion of the hospitalized human influenza A-related viral pneumonia patients in the 35-49 age group was more than that of the B pneumonia patients, and the proportion in the $\geq 65$ years age group was relatively less than that of the $\mathrm{B}$ pneumonia patients. Some studies have reported that influenza B mainly affects the elderly and people with underlying diseases [6, 7]; however, pH1N1 mainly affects young adults, similar to our research. Early-life exposure to an antigenically related virus, i.e., the A (H1N1) strain that circulated after the 1918 pandemic and prior to the $1957 \mathrm{~A}$ (H2N2) pandemic might mitigate the severity for the pH1N1 strain in older individuals; this phenomenon explained the survival of elderly in the pandemic. In China, the old people retire at 60 years of age and have more opportunities to shop in live-animal markets, therefore more likely to be exposed to the livepoultry, it can partially explain why the H7N9 patients have more comorbid conditions.

In the aspect of clinical characteristics and diagnostic findings, CK was designated as a biomarker of severity in $\mathrm{pH} 1 \mathrm{~N} 1$ infection; the elevation of $\mathrm{CK}$ was associated with complications, increased length of ICU stay, and healthcare resources [8]. Another study included 155 hospitalized adult patients with $\mathrm{pH} 1 \mathrm{~N} 1$; LDH was an independent risk factor of hospital death as assessed by multivariate logistic regression analysis [9]. The elevation of DD may be caused by the embolism of the small 
Table 3 Comparison of complications, treatment, and clinical outcomes of three types hospitalized influenza-related viral pneumonia patients

\begin{tabular}{|c|c|c|c|c|c|}
\hline \multirow[t]{2}{*}{ Characteristics } & \multirow{2}{*}{$\begin{array}{l}B(n=59) \\
\text { (a) }\end{array}$} & \multirow{2}{*}{$\begin{array}{l}A(n=138) \\
\text { (b) }\end{array}$} & \multirow{2}{*}{$\begin{array}{l}\text { H7N9 }(n=18) \\
\text { (c) }\end{array}$} & \multicolumn{2}{|c|}{$p$-value among } \\
\hline & & & & (a) and (b) & (a), (b), and (c) \\
\hline Complications & $7(12)$ & $16(12)$ & $4(22.2)$ & 0.957 & 0.411 \\
\hline Shock & $1(1.7)$ & $9(6.5)$ & $1(5.6)$ & 0.289 & 0.315 \\
\hline Acute kidney injury & $5(8.5)$ & $11(8)$ & $2(11.1)$ & 1 & 0.793 \\
\hline Rhabdomyolysis & $1(1.7)$ & $1(0.7)$ & $1(5.6)$ & 0.51 & 0.147 \\
\hline \multicolumn{6}{|l|}{ Treatment } \\
\hline Oxygen therapy, no. (\%) & $44(74.6)$ & $101(73.2)$ & $18(100)$ & 0.84 & 0.022 \\
\hline Antiviral treatment, no. (\%) & $52(88)$ & $152(93)$ & $18(100)$ & 0.72 & 0.388 \\
\hline Oseltamivir & $36(69.2)$ & $70(56.5)$ & $0(0)$ & 0.114 & $<0.001$ \\
\hline Peramivir & $9(17.3)$ & $32(25.8)$ & $0(0)$ & 0.224 & 0.02 \\
\hline Both & $7(13.5)$ & $22(17.7)$ & $18(100)$ & 0.485 & $<0.001$ \\
\hline $\begin{array}{l}\text { Timing from onset of illness to administration of antivi- } \\
\text { ral therapy, median (IQR) (days) }\end{array}$ & $6(3-14)$ & $7(5-10.8)$ & $4(3-8.3)$ & 0.797 & 0.089 \\
\hline $0-2$ & $9(17.6)$ & $14(11.3)$ & $1(18)$ & 0.258 & 0.384 \\
\hline $3-5$ & $12(23.5)$ & $31(25)$ & $57(34.8)$ & 0.837 & 0.091 \\
\hline$\geq 6$ & $30(58.8)$ & $79(63.7)$ & $8(44.4)$ & 0.544 & 0.281 \\
\hline $\begin{array}{l}\text { Timing from administration of antiviral therapy to virus } \\
\text { negative, median (IQR) }\end{array}$ & $11(6-17.75)$ & $10(6-14.5)$ & $5(2.8-10)$ & 0.26 & 0.007 \\
\hline Admission to ICU, no. (\%) & $4(6.8)$ & 27 (19.6) & $15(83.3)$ & 0.024 & 0.054 \\
\hline \multicolumn{6}{|l|}{ Mechanical ventilation } \\
\hline Noninvasive & $6(10.2)$ & $14(10.1)$ & $0(0)$ & 0.996 & 0.528 \\
\hline Invasive & $2(3.4)$ & $23(16.7)$ & $7(38.9)$ & 0.001 & 0.001 \\
\hline Extracorporeal membrane oxygenation & $0(0)$ & $2(1.4)$ & $2(11.1)$ & 1 & 0.048 \\
\hline Blood purification & $4(6.8)$ & $3(2.2)$ & $2(11.1)$ & 0.2 & 0.072 \\
\hline Antibiotics & $56(94.9)$ & $134(97.1)$ & $17(94.4)$ & 0.430 & 0.416 \\
\hline Antifungal & $22(37.3)$ & $42(30.4)$ & $13(72.2)$ & 0.347 & 0.002 \\
\hline Glucocorticoids & $24(41)$ & $77(56)$ & $18(100)$ & 0.052 & $<0.001$ \\
\hline \multicolumn{6}{|l|}{ Clinical outcome } \\
\hline Death & $5(8.5)$ & $13(9.4)$ & $0(0)$ & 0.833 & 0.542 \\
\hline Total hospitalization expenses (Yuan), median (IQR) & $\begin{array}{l}18,316.8(11,111.1- \\
35,750.5)\end{array}$ & $\begin{array}{l}25,642.3(13,184.5- \\
53,805.7)\end{array}$ & $\begin{array}{l}\text { - } 66,095.6(42,450.6- \\
129,574.2)\end{array}$ & -0.094 & $<0.001$ \\
\hline
\end{tabular}

Timing from onset of illness to administration of antiviral therapy: For human influenza A, there were 14 miss dates; for B, there were 8 miss dates Timing from administration of antiviral therapy to virus negative: For human influenza $A$, there were 73 miss dates; for $B$, there were 39 miss dates Total hospitalization expenses: For human influenza $A$, there were 14 miss dates; for $B$, there were 6 miss dates

$I C U$ intensive care unit, IQR interquartile range

pulmonary vessels, then the pulmonary ventilation and blood flow ratio became abnormal, and the blood oxygen saturation declined. Finally, the rate of mortality was elevated; however, this hypothesis needs further substantiation. A lymphocyte count of $<300$ lymphocytes/ $\mu \mathrm{L}$ was observed in a subgroup of patients with poor outcome in a study encompassing 239 inpatients with confirmed influenza virus infection [10]. Thus, we can conclude that the proportion of elevated CK, LDH, $\mathrm{DD}$, and lymphocytopenia was positively relative to the severity of influenza. In this study, the elevated LDH and lymphocytopenia in hospitalized human influenza
A-related viral pneumonia patients was higher than that in B pneumonia patients, and the elevated CK, LDH, DD, and lymphocytopenia in hospitalized H7N9related viral pneumonia patients was higher than that in human influenza A and B pneumonia patients. The proportion of ICU admission and invasive mechanical ventilation in hospitalized human influenza A-related viral pneumonia patients was higher than that in B pneumonia patients. The proportion of IMV and the median value of hospitalization expense in hospitalized H7N9related viral pneumonia patients were higher than that in human influenza A and B pneumonia patients. Taken 
Table 4 Multivariate analysis of factors associated with death due to three types hospitalized influenza-related viral pneumonia patients

\begin{tabular}{|c|c|c|}
\hline Variables & OR $(95 \% \mathrm{Cl})$ & p-value \\
\hline White blood cell count $>10,000 / \mathrm{mm}^{3}$ & $7.22(1.47-35.58)$ & 0.015 \\
\hline Hemoglobulin (g/dL) & & 0.1 \\
\hline Platelets count $/ \mathrm{mm}^{3}$ & & 0.851 \\
\hline C-reactive protein (mg/L) & & 0.772 \\
\hline Procalcitonin $>0.5 \mathrm{ng} / \mathrm{mL}$ & & 0.621 \\
\hline D-dimer $>2100 \mathrm{mg} / \mathrm{L}$ & & 0.387 \\
\hline Pro-B-type natriuretic peptides (pg/mL) & & 0.231 \\
\hline $\begin{array}{l}\text { Positive bacterial culture (blood or } \\
\text { sputum) on presentation or during } \\
\text { hospitalization }\end{array}$ & $6.27(1.36-28.85)$ & 0.018 \\
\hline $\begin{array}{l}\text { Computed tomography consistent with } \\
\text { pulmonary consolidation at admission }\end{array}$ & & 0.427 \\
\hline Shock ${ }^{\mathrm{a}}$ & $13.16(2.06-84.07)$ & 0.006 \\
\hline
\end{tabular}

OR odds ratio, $\mathrm{Cl}$ confidence interval

Pro-B-type natriuretic peptides: For human influenza A, there were 62 miss dates; for $\mathrm{B}$, there were 42 miss dates; for $\mathrm{H7N} 9$, there were 11 miss dates

${ }^{\text {a }}$ Shock at any point during the illness

together, it can be concluded that the hospitalized human influenza A-related viral pneumonia patients was severer than B pneumonia patients, but milder than H7N9 pneumonia patients. A study consisting of 57 cases of H7N9 patients and 14 cases of pH1N1 patients demonstrated that the proportion of acute respiratory distress syndrome to H7N9 was much higher than that of pH1N1 [11], which was also observed in the current study. Furthermore, the proportion of ICU admission and IMV to pH1N1 was twofold higher than that of $\mathrm{B}$, and no difference was detected in the mortality as reported by a study including 2791 cases of adult patients [12]. Another study reported that the mortality of adults influenza B patients was similar to that of $\mathrm{pH} 1 \mathrm{~N} 1$ patients [13]. Although all the influenza viruses infect the respiratory epithelium from the nasal passages to bronchioles, pH1N1 tends to infect pneumocytes and interalveolar macrophages, causing extensive areas of inflammation in the alveoli, which could partially explain the increased severity of pH1N1 [1417]. Hospitalized influenza B-related viral pneumonia mainly affects the elderly and those with underlying diseases, rendering them as severe cases, such that the mortality of B pneumonia patients was elevated and similar to human influenza A pneumonia patients. Hypercytokinemia is characterized by the over-production of various proinflammatory cytokines and plays an significant role in disease severity and mortality in H5N1 patients [18]. Compared with pH1N1 infection, $\mathrm{H} 7 \mathrm{~N} 9$ virus infection tends to induce higher cytokine expression, resembling the cytokine storm observed in H5N1 infection [19], which could partially explain why the H7N9 infection was severer than pH1N1.

The World Health Organization Guidelines recommended that prompt empirical antiviral treatment should be initiated when influenza is suspected, even before laboratory results are known [20]. Improved clinical outcomes have been described among adults treated with antiviral drugs after hospitalization or up to 5 days from illness onset [21-23]. Early antiviral therapy within 2 days of illness accelerated viral shedding and reduced the mortality in patients with H7N9 viral infection [24]. Moreover, compared to early antiviral therapy, H7N9 patients with delayed antiviral therapy became severe cases [25]. Interestingly, in a study comprising of 82 cases of H7N9 virus infection, the time of onset of illness to administration of antiviral therapy was 6 days (IQR: $4-8$ ), longer than that in the current study 4 days (IQR:3-8.3), and the administration of antiviral therapy to virus-negative time of the study was 7 days (IQR: 5-9), also longer than 5.5 days (IQR: 2.8-10) in the current study; the mortality was $34.1 \%$ [26]. Gao et al. [27] reported that the rate of glucocorticoid use of the H7N9 cases was $62.2 \%$, lower than our study $100 \%$ and the mortality was $27 \%$. The mortality of hospitalized H7N9-related viral pneumonia patients was much higher than that of human influenza $\mathrm{A}$ and $\mathrm{B}$ pneumonia. However, in the current study, the mortality of hospitalized H7N9-related viral pneumonia patients was lower than before and similar to human influenza A and B pneumonia. This phenomenon might be explicated by the initial antiviral time relatively early than before and the rate of glucocorticoid use for H7N9 was high. All our patients received oseltamivir with peramivir that also may reduce the mortality, although these findings need to be substantiated further. In the current study, the proportion of early antiviral therapy in the three types of hospitalized influenza-related viral pneumonia patients was similar.

Nevertheless, the present study has several limitations. First, influenza testing was ordered at the physicians' discretion, and therefore, not all individuals with influenza were tested, or testing could be biased towards severe cases. However, this bias would not affect our main findings because influenza testing was ordered independently of the knowledge of the virus type or subtype. Second, we only included the hospitalized influenza-related viral pneumonia patients and excluded the outpatient cases and hospitalized patients without influenza-related viral pneumonia, such that it cannot reflect the whole disease spectrum. Finally, because the RT-PCR was not accurate absolutely, the real influenza-positive patients may be diagnosed as negative. 


\section{Conclusion}

In summary, hospitalized influenza B-related viral pneumonia mainly affects the elderly and individuals with underlying diseases, while human influenza A pneumonia mainly affects the young adults; however, the mortality was comparative. The hospitalized human influenza A-related viral pneumonia patients was severer than B pneumonia patients, but milder than H7N9 pneumonia patients. Pulmonary consolidation and positive bacterial culture (sputum) at the time of presentation or during hospitalization were independently associated with IMV due to three types of hospital influenza-related viral pneumonia patients. On the other hand, shock, white blood cell count $>10,000$ / $\mathrm{mm}^{3}$, and positive bacterial culture (blood or sputum) at the time of presentation or during hospitalization were associated with death in such patients.

\section{Abbreviations \\ IMV: Invasive mechanical ventilation; pH1N1: Influenza A (H1N1) pdm09; H7N9: Avian-origin influenza A (H7N9); RT-PCR: Reverse transcriptase-polymer- ase chain reaction; NPS: Nasopharyngeal swabs; BMI: Body mass index; IQR: Interquartile range; AST: Aspartate aminotransferase; LDH: Lactate dehydro- genase; DD: D-dimer; CK: Creatine kinase; ICU: Intensive care unit; ECMO: Extracorporeal membrane oxygenation; $\mathrm{PaO}_{2}: \mathrm{FiO}_{2}$ : Partial pressure arterial oxygen/fraction of inspired oxygen; OR: Odds ratio; $\mathrm{Cl}$ : Confidence interval; SCr: Serum creatinine.}

\section{Supplementary Information}

The online version contains supplementary material available at https://doi. org/10.1186/s12879-021-06485-x.

Additional file 1. Definitions of Obesity, The current smoking status, Alcohol abuse, Confirmed human influenza A or B, Comfirmed avianorigin A (H7N9), lymphocytopenia, Rhabdomyolysis, Acute kidney injury, Immunosuppression, Early antiviral therapy, The exposure to live poultry.

Additional file 2. Table S1: Univariate Analysis of Factors Associated with Invasive Mechanical Ventilation due to Three Types Hospitalized Influenzarelated Viral Pneumonia Patients.

Additional file 3. Table S2: Univariate Analysis of Factors Associated with Death due to Three Types Hospitalized Influenza-related Viral Pneumonia Patients.

Additional file 4. Table S3: Multivariate Analysis of Factors Associated with Invasive Mechanical Ventilation due to Three Types of Hospital Influenza-related Viral Pneumonia Patients.

\section{Acknowledgements}

We acknowledge the contributions of other clinical and technical staff of the First Affiliated Hospital, College of Medicine, Zhejiang University.

\begin{abstract}
Authors' contributions
Study concept and design: BF and LT. Acquisition of data: BF, ZW, LH, ZC and PZ. Analysis and interpretation of data: BF, ZW and LT. Drafting of the manuscript: BF, ZW, LH, ZC, PZ, QS, SG, QX, HF and LT. Critical revision of the manuscript for intellectual content: BF, ZW, LH, ZC, PZ, QS, SG, QX, HF and LT. All authors read and approved the manuscript.
\end{abstract}

\section{Funding}

This work was supported by Grants from the Natural Science Foundation of China (No. 81872672) and National Science and Technology Major Project (No.
2017ZX10204401). These funds were helpful in the design of the study and collection, analysis, and interpretation of data and in writing the manuscript.

\section{Availability of data and materials}

All data generated or analysed during this study are either included in this published article and its additional information files or are available from the corresponding author on reasonable request.

\section{Declarations}

\section{Ethics approval and consent to participate}

The local ethics committee (The First Affiliated Hospital, College of Medicine, Zhejiang University) approved this study, the data used in this study was anonymised before its use.

\section{Consent to publish}

Not applicable.

\section{Competing interests}

The authors declare that they have no competing interests.

\section{Author details}

${ }^{1}$ Department of Infectious Diseases, Hangzhou TCM Hospital Affiliated to Zhejiang Chinese Medical University, Hangzhou 310007, People's Republic of China. ${ }^{2}$ State Key Laboratory for Diagnosis and Treatment of Infectious Disease, National Clinical Research Center for Infectious Diseases, Collaborative Innovation Centre for Diagnosis and Treatment of Infectious Diseases, The First Affiliated Hospital, College of Medicine, Zhejiang University, No.79 Qingchun Road, Hangzhou 310003, Zhejiang, People's Republic of China. ${ }^{3}$ Department of Critical Care Medicine, The First Affiliated Hospital, College of Medicine, Zhejiang University, Hangzhou 310003, People's Republic of China. ${ }^{4}$ Department of Neurosurgery, The First Affiliated Hospital, College of Medicine, Zhejiang University, Hangzhou 310003, People's Republic of China. ${ }^{5}$ Department of Dermatology, The First Affiliated Hospital, College of Medicine, Zhejiang University, Hangzhou 310003, People's Republic of China. ${ }^{6}$ Department of Nosocomial Infection, The First Affiliated Hospital, College of Medicine, Zhejiang University, Hangzhou 310003, People's Republic of China. ${ }^{7}$ Shulan(Hangzhou) Hospital Affiliated to Zhejiang Shuren University Shulan International Medical College, Hangzhou 310006, People's Republic of China.

Received: 23 February 2020 Accepted: 28 July 2021

Published online: 25 September 2021

\section{References}

1. Brammer $L$, Blanton $L$, Epperson $S$, et al. Surveillance for influenza during the 2009 influenza A (H1N1) pandemic-United States, April 2009-March 2010. Clin Infect Dis. 2011;52:S27-35

2. Perez-Padilla R, de la Rosa-Zamboni D, Ponce de Leon S, INER Working Group on Influenza, et al. Pneumonia and respiratory failure from swineorigin influenza A (H1N1) in Mexico. N Engl J Med. 2009;361(7):680-9.

3. Aebi T, Weisser M, Bucher E, Hirsch HH, Marsch S, Siegemund M. Coinfection of influenza B and Streptococci causing severe pneumonia and septic shock in healthy women. BMC Infect Dis. 2010;10:308 (1471-2334 (Linking)).

4. Kim YH, Kim HS, Cho SH, Seo SH. Influenza B virus causes milder pathogenesis and weaker inflammatory responses in ferrets than influenza $A$ virus. Viral Immunol. 2009;22(6):423-30.

5. Number of confirmed human cases of avian influenza $A(H 7 N 9)$ reported to WHO. Geneva: World Health Organization. http://www.who.int/influ enza/human_animal_interface/influenza_h7n9/05_ReportWebH7N9Nu mber.pdf. Accessed May 2013.

6. Thompson WW, Shay DK, Weintraub E, Brammer L, Bridges CB, Cox NJ, et al. Influenza-associated hospitalizations in the United States. JAMA. 2004;292(11):1333-40.

7. Treanor JJ. Virus de la gripe. In: Mandell GL, Bennett JE, Dolin R, editors. Enfermedades infecciosas: principios y practica, vol. 2. 6th ed. Madrid: Elsevier INC; 2005. p. 2060-85. 
8. Borgatta B, Pérez M, Vidaur L, et al. Elevation of creatine kinase is associated with worse outcomes in 2009 pH1N1 influenza A infection. Intensive Care Med. 2012;38:1152-61.

9. Xi X, Yuan Xu, Jiang Li, et al. Hospitalized adult patients with 2009 influenza $\mathrm{A}(\mathrm{H} 1 \mathrm{~N} 1)$ in Beijing, China: risk factors for hospital mortality. BMC Infect Dis. 2010;10:256.

10. Lalueza A, Folgueira D, Díaz-Pedroche C, et al. Severe lymphopenia in hospitalized patients with influenza virus infection as a marker of a poor outcome. Infect Dis. 2019:51(7):543-6.

11. Wenrui Wu, Shi D, Fang D, et al. A new perspective on C-reactive protein in H7N9 infections. Int J Infect Dis. 2016;44:31-6.

12. Chaves SS, Aragon D, Bennett N, et al. Patients hospitalized with laboratory confirmed influenza during the 2010-2011 influenza season: exploring disease severity by virus type and subtype. J Infect Dis. 2013;208:1305-14.

13. Gutiérrez-Pizarraya A, Pérez-Romero P, Alvarez R, et al. Unexpected severity of cases of influenza B infection in patients that required hospitalization during the first postpandemic wave. J Infect. 2012;65:423-30.

14. Huang SS, Banner D, Fang Y, et al. Comparative analyses of pandemic H1N1 and seasonal H1N1, H3N2, and influenza B infections depict distinct clinical pictures in ferrets. PLoS ONE. 2011;6:e27512.

15. Guarner J, Falcón-Escobedo R. Comparison of the pathology caused by H1N1, H5N1, and H3N2 influenza viruses. Arch Med Res. 2009;40:655-61.

16. Itoh $Y$, Shinya K, Kiso M, et al. In vitro and in vivo characterization of new swine-origin H1N1 influenza viruses. Nature. 2009;460:1021-5.

17. Munster VJ, de Wit E, van den Brand JM, et al. Pathogenesis and transmission of swine-origin $2009 \mathrm{~A}(\mathrm{H} 1 \mathrm{~N} 1)$ influenza virus in ferrets. Science. 2009;325:481-3.

18. Zhou J, Wang D, Gao R, Zhao B, Song J, Qi X, et al. Biological features of novel avian influenza A (H7N9) virus. Nature. 2013;499:500-3.

19. de Jong MD, Simmons CP, Thanh TT, Hien VM, Smith GJ, Chau TN, et al. Fatal outcome of human influenza $\mathrm{A}(\mathrm{H} 5 \mathrm{~N} 1)$ is associated with high viral load and hypercytokinemia. Nat Med. 2006;12:1203-7.
20. Centers for Disease Control and Prevention. Antiviral agents for the treatment and chemoprophylaxis of influenza. Recommendations of the Advisory Committee on Immunization Practices (ACIP). MMWR. 2011;60:1-24.

21. Lee N, Choi KW, Chan PK, et al. Outcomes of adults hospitalised with severe influenza. Thorax. 2010;65:510-5.

22. McGeer A, Green KA, Plevneshi A, et al. Antiviral therapy and outcomes of influenza requiring hospitalization in Ontario, Canada. Clin Infect Dis. 2007:45:1568-75

23. Louie JK, Yang S, Acosta M, et al. Treatment with neuraminidase inhibitors for critically ill patients with influenza A (H1N1)pdm09. Clin Infect Dis. 2012:55:1198-204.

24. Zheng $S$, Tang $L, G a o ~ H$, et al. Benefit of early initiation of neuraminidase inhibitor treatment to hospitalized patients with avian influenza A (H7N9) virus. Clin Infect Dis. 2018;66(7):1054-60

25. Leung YH, To MK, Lam TS, Yau SW, Leung OS, Chuang SK. Epidemiology of human influenza A(H7N9) infection in Hong Kong. J Microbiol Immunol Infect. 2015:50:183-8

26. Zhang Y, Gao H, Liang W, et al. Efficacy of oseltamivir-peramivir combination therapy compared to oseltamivir monotherapy for Influenza A (H7N9) infection: a retrospective study. BMC Infect Dis. 2016;16:76.

27. Gao H-N, Hong-Zhou Lu, Cao B, et al. Clinical findings in 111 cases of influenza A (H7N9) virus infection. N Engl J Med. 2013;368:2277-85.

\section{Publisher's Note}

Springer Nature remains neutral with regard to jurisdictional claims in published maps and institutional affiliations.
Ready to submit your research? Choose BMC and benefit from:

- fast, convenient online submission

- thorough peer review by experienced researchers in your field

- rapid publication on acceptance

- support for research data, including large and complex data types

- gold Open Access which fosters wider collaboration and increased citations

- maximum visibility for your research: over $100 \mathrm{M}$ website views per year

At BMC, research is always in progress.

Learn more biomedcentral.com/submissions 